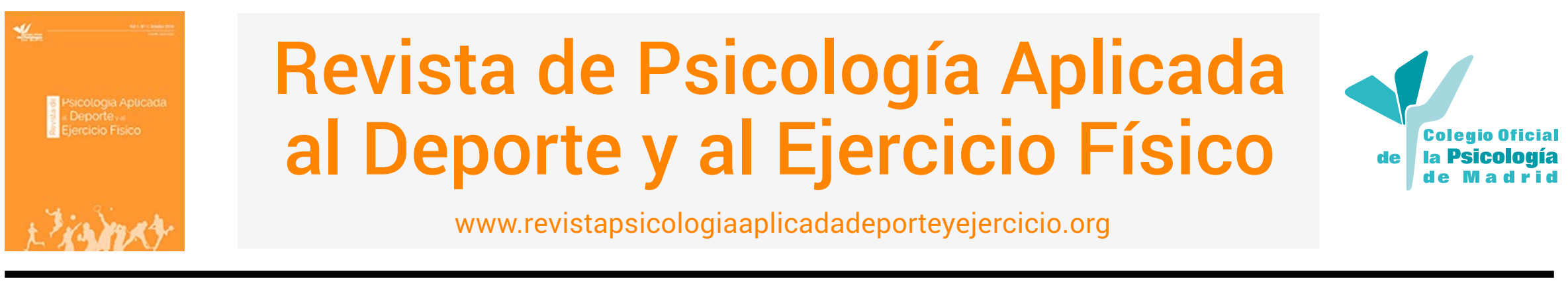

\title{
Entrevista a Juan María Gavaldá por Manuel Aguilar Marchal
}

\author{
¿Podrías realizar una breve descripción de la AEEB \\ y de quién es Juan María Galvaldá?
}

La Asociación Española de Entrenadores de Baloncesto (AEEB), fundada en el año 1973, fue pionera entre las asociaciones de entrenadores y su aportación decisiva en la constitución en 1977 de la Asociación Mundial de Entrenadores (WABC). En septiembre de 2007 impulsó la constitución de la Unión Europea de Asociaciones de Entrenadores de Baloncesto (EUABC), asumiendo la presidencia en el primer mandato, y es miembro del Consejo Nacional de Entrenadores Deportivos (CNED).

La relación institucional de la AEEB le permite trabajar de la mano de las Federaciones Autonómicas, Federación Española de Baloncesto, Asociación de Clubes de Baloncesto, Consejo Superior de Deportes, así como otras instituciones nacionales e, internacionalmente, con FIBA, Euroliga y NBA. Un baloncesto del cual, y como siempre ha sido, la figura del ENTRENADOR se convierte en pieza fundamental para afrontar el futuro. Para más información sobre AEEB, ver la página web: https://aeeb.es/

En el año 2005, fui elegido presidente de AEEB, cargo que todavía ostento, en el 2007 de la Asociación Europea de Entrenadores (EUABC) y en el 2009 del Consejo Nacional de Entrenadores.

El mío es el caso de un hombre que encontró un gran significado en enseñar a jugar al baloncesto cuando sólo tenía 17 años. En aquel momento me gustaba mucho jugar, pero descubrí que enseñar a jugar era muy divertido, marcó mi vida.

Durante 14 años entrené baloncesto femenino, los últimos cinco en primera división, para seguidamente pasar a baloncesto masculino. Primero en Andorra, quedando campeones de España con ascenso a la Primera B. Posteriormente, fiché por el TDK Manresa, Valvi Girona, ambos de liga ACB, y por TVE como comentarista técnico de los partidos televisados nacionales e internacionales. Luego, fui a entrenar, también en liga ACB, al Argal Huesca.
A partir de ese momento, decido compaginar mi profesión de arquitecto con mi afición por entrenar, compitiendo y quedando campeones varias veces en liga EBA, LEB Plata y LEB Oro en Cornellá y Valls.

Actualmente, ejerzo como arquitecto en diferentes proyectos y presido $A E E B$, liderando equipos de trabajo y gente que apoya, con mucha generosidad, nuestros objetivos para poder desarrollar proyectos deportivos, sociales y educativos, como el que nos va a relacionar con el mundo de la Psicología.

\section{En julio de 2020 tuvo lugar la firma del convenio de colaboración entre AEEB y el COPM, ¿qué destacarías de esta colaboración y qué beneficios reporta para ambos colectivos?}

El convenio entre nuestra entidad, AEEB, con el Colegio Oficial de la Psicología de Madrid (COPM), y en su extensión, a todos los niveles, persigue definir un marco absolutamente necesario en el contexto del mundo de deporte. No sé si podemos hablar tanto de Psicología del Deporte o Psicología en el Deporte. Creo que psicólogos/as y entrenadores/as somos dos activos muy importantes para el desarrollo de la formación, gestión de las emociones, mejora del rendimiento y crecimiento personal de la gente y que ambos colectivos lo canalizamos con diferentes acciones que realizamos con entrega y esfuerzo.

Estoy tremendamente ilusionado con ello porque forma parte de un ánimo muy concreto que tiene nuestra Asociación, que es ayudar a mejorar a las personas, en cualquiera de las áreas de su vida. Nosotros tenemos muchos jugadores y jugadoras durante el ejercicio de nuestra carrera. Sin embargo, lo que realmente hacemos es formar personas tanto o más que deportistas. Por ello, es un concepto que tenemos que tener muy claro en cuanto a la solidaridad responsable respecto a esa formación. 
Teniendo en cuenta la gran experiencia con la que cuentas, tanto en la faceta de entrenador de élite, como en la de presidente de una gran Asociación, ¿cómo ves la relación actual entre la Psicología del Deporte y el baloncesto en España?

La relación entre la Psicología del deporte y el baloncesto creo que tiene unos vínculos absolutamente necesarios e inevitables de presente y futuro. Vamos a trabajar conjuntamente en experiencias en los grandes entornos el mundo del deporte.

El deporte en general y en especial el baloncesto, al que yo me debo ceñir, creo que está en una situación en estos momentos envidiable y desde una institución de entrenadores, donde parte de nuestra idea es ayudar a la formación, creemos que es ineludible que la reconstrucción del tejido deportivo tras estos tiempos de paro o dificultades, venga por tener aportación con nuevas herramientas, nuevos conocimientos y nuevas formas de proceder.

Por tanto, personalmente como presidente, y desde luego toda la institución, estamos muy ilusionados en poder vincular al psicólogo/a con el mundo del baloncesto y al entrenador/a con el mundo de la Psicología.

\section{¿Cómo sería el perfil ideal del entrenador/a en el deporte base?}

El perfil de un entrenador de deporte de base debe encajar absolutamente en un punto referencial: ese tipo de entrenadores son formadores de personas, utilizan una herramienta como es el deporte, baloncesto, para canalizar las instrucciones y sobre todo las ideas fundamentales de forja de una persona a través de ejercicios, entrenamientos, partidos mensajes, correcciones, etc. Si ese ADN falla y no se cumple como requisito principal, encaja difícilmente en lo que es un formador de personas. Por tanto, cualquier valoración exclusivamente deportiva, excesivamente vinculada a la victoria y totalmente centrada en "tienes que hacer eso y eso y lo otro porque lo dice el entrenador" no funciona en el deporte base o no debe funcionar. Por tanto, cualquier tipo de concepto que sea contrario a la forja de las personas que tienes a tu cargo, a la correcta complementación del trabajo que hacen sus padres, sus familias en cuanto al desarrollo personal de esa niña o niño, de ese jugador o jugadora es absolutamente inviable con un concepto lógico y entendible del siglo XXI.

El vínculo con la Psicología que debe acompañar al deporte base está fuertemente relacionado con el concepto educativo como tal. Aprender no es solo aplicable a las matemáticas, geografía, historia, lenguas, etc., sino que, además, es forjar una personalidad acorde con lo que va a tener que vivir y por tanto, el conocimiento junto a las emociones y los comportamientos harán que esa persona se conduzca y proceda de las mejores maneras posibles para ser un activo para el desarrollo de la prosperidad. Es muy interesante, desde este enfoque, que nos vinculemos entrenadores/as y psicólogos/as para caminar conjuntamente en la formación y en la adecuación del crecimiento personal de todas esas jugadores y jugadoras que tenemos a nuestras órdenes.

\section{¿Cómo sería el perfil ideal del entrenador/a en el deporte profesional?}

Por otra parte, el perfil del entrenador/a profesional es un perfil muy amplio a tener en cuenta. En España, atesoramos una gran cantidad de los mejores entrenadores del mundo en esta disciplina. Muchos de ellos, estarían cualificados para proyectos internacionales de gran envergadura, pues sus perfiles son multidisciplinares.

A día de hoy, el perfil del profesional tiene que ser muy transversal, con mucha capacidad operativa dentro de un engranaje, tal y como demanda una gran empresa que es un club y además, tener conocimientos amplios y heterogéneos como el desarrollo de capacidades operativas, dotes para elaborar un buen tejido colectivo y ser canalizador del trabajo de grupo, entre otras muchas competencias y habilidades.

Paralelamente, el técnico de élite debe contar con apoyo experto en el tratamiento emocional de diferentes ámbitos de los deportistas, incluso el suyo propio como líder y cabeza de un proyecto, así como su cuadro técnico. El control en el modelado de las emociones es muy importante, como estamos viendo en deportes de alto rendimiento a nivel nacional e internacional, donde no es extraño haber incorporado no un psicólogo, sino un equipo de trabajo a su cargo, buscando la mejora en ese apartado y la máxima rentabilidad de los esfuerzos de las personas que están colaborando y dedicándose a la tarea deportiva. Por tanto, creo que, en el ámbito profesional, esto significa un gran salto de calidad. No se habla del psicólogo/a, sino del área de Psicología de ese grupo/ franquicia/ club. Yo creo que es la mayor singularidad diferencial entre lo que debe ser el deporte en un equipo profesional y un equipo de formación.

\section{En este momento, ¿cuál te parece que sería el camino a seguir para consolidar la Psicología del deporte en el baloncesto español?}

No creo que haya un único camino para consolidar la Psicología dentro del baloncesto español, sino que deben ser varios vehículos que lleven en la misma dirección a di- 
ferentes contenidos y, por tanto, creo que es un esfuerzo, y nuevamente utilizo el término, transversal. No solamente psicólogos, sino organismos organizativos de ligas, clubes, entrenadores y jugadores.

Creo que, tanto a nivel de élite como a nivel de base, la llegada de los psicólogos/as debe ser un trazado continuo, sólido, duradero en extensión y con calidad.

Hay un futuro amplísimo para vincular el mundo de la Psicología al deporte y, si hablamos de baloncesto, lo veo concretamente en que los psicólogos/as mejorarán las capacidades individuales y de grupos.

\section{¿Qué le podría aportar a un psicólogo afiliarse a AEEB?}

El vínculo con la AEEB permitirá que los/as psicólogos/ as puedan generar mejoras a través de los conocimientos que tienen, de la combinación de experiencias y la oferta de oportunidades que adquirirán conectando con el propio entrenador. Ofreceremos la posibilidad de integrarse en nuestro colectivo de la $A E E B$, en el formato justo para que les sea útil participar con nuestra institución en diferentes programas y acciones.

\section{Finalmente, para terminar, nos gustaría que pudieras compartir un mensaje para los entrenadores de baloncesto y psicólogos/as del deporte.}

Mi mensaje final es decir al mundo del deporte que, a través de una colaboración pionera entre psicólogos/as y entrenadores/as, abrimos una autopista de dos sentidos para enriquecer este sector sin distinción de niveles, especialidades o categorías. ¡Os estamos esperando! 